\title{
Abnormal Dysbindin Expression in Cerebellar Mossy Fiber Synapses in the mdx Mouse Model of Duchenne Muscular Dystrophy
}

\author{
Roy V. Sillitoe, ${ }^{1}$ Matthew A. Benson, ${ }^{2}$ Derek J. Blake, ${ }^{2}$ and Richard Hawkes ${ }^{1}$ \\ ${ }^{1}$ Department of Cell Biology and Anatomy, and Genes and Development Research Group, Faculty of Medicine, The University of Calgary, Calgary, Alberta \\ T2N 4N1, Canada, and 2Department of Pharmacology, University of Oxford, Oxford, OX1 3QT, United Kingdom
}

The dystrophin-associated protein complex (DPC), comprising sarcoglycans, dystroglycans, dystrobrevins, and syntrophins, is a component of synapses both in muscle and brain. Dysbindin is a novel component of the DPC, which binds to $\beta$-dystrobrevin and may serve as an adaptor protein that links the DPC to an intracellular signaling cascade. Disruption of the DPC results in muscular dystrophy, and mutations in the human ortholog of dysbindin have been implicated in the pathogenesis of schizophrenia. In both cases, patients also present with neurological symptoms reminiscent of cerebellar problems. In the mouse cerebellum, dysbindin immunoreactivity is expressed at high levels in a subset of mossy fiber synaptic glomeruli in the granular layer. Lower levels of dysbindin immunoreactivity are also detected in Purkinje cell dendrites. In the cerebellar vermis, dysbindin-immunoreactive glomeruli are restricted to an array of parasagittal stripes that bears a consistent relationship to Purkinje cell parasagittal band boundaries as defined by the expression of the respiratory isoenzyme zebrin II/aldolase c. In a mouse model of Duchenne muscular dystrophy, the $m d x$ mutant, in which dystrophin is not expressed, there is a dramatic increase in the number of dysbindin-immunoreactive glomeruli in the posterior cerebellar vermis. Moreover, the topography of the terminal fields is disrupted, replacing the stripes by a homogeneous distribution. Abnormal synaptic organization in the cerebellum may contribute to the neurological problems associated with muscular dystrophy and schizophrenia.

Key words: Purkinje cell; dystrophin; zebrin II; unipolar brush cell; choline acetyltransferase; schizophrenia

\section{Introduction}

The dystrophin-associated protein complex (DPC) of the neuromuscular junction is comprised of three distinct components: the sarcoglycan, dystroglycan, and cytoplasmic complexes, which include $\alpha$ - and $\beta$-dystrobrevin and the $\alpha$-, $\beta_{1^{-}}$, and $\beta$-syntrophins (for review, see Blake et al., 2002). Biochemical analysis of postsynaptic density-enriched synaptosomal proteins and immunocytochemical localization of several DPC members [e.g., dystrophin (Lidov et al., 1990), $\alpha$-dystrobrevin, $\beta$-dystrobrevin (Blake et al., 1998, 1999), and utrophin (Knuesel et al., 2000)] suggests that DPC-like complexes are also present in the brain (Blake et al., 1999). Several distinct brain DPCs have been tentatively identified based on the selective distributions of dystrophin binding partners such as $\beta$-dystrobrevin and the syntrophins (Blake et al., 1999). Disruption of the DPC results in muscular dystrophy and, consistent with a DPC function in the brain, mu-

Received Feb. 26, 2003; revised April 29, 2003; accepted May 28, 2003.

This work was supported by grants from the Canadian Institutes of Health Research (R.H.), Canadian Institutes of Health Research Training Program in Genetics, Child Development and Health (R.V.S.), and the Wellcome Trust (D.J.B.). D.J.B. is a Wellcome Trust Senior Fellow. We thank Dr. Sarah McFarlane for advice and Dr. Jan Braun for antibodies.

Correspondence should be addressed Dr. R. Hawkes, Department of Cell Biology and Anatomy, Faculty of Medicine, University of Calgary, 3330 Hospital Drive Northwest, Calgary, Alberta T2N 4N1, Canada. E-mail: rhawkes@ucalgary.ca.

Copyright $\odot 2003$ Society for Neuroscience $\quad$ 0270-6474/03/236576-10\$15.00/0 tations in dystrophin also cause multiple central neurological symptoms (Blake and Kroger, 2000; Hinton et al., 2000).

Recently, a novel member of the DPC, the $40 \mathrm{kDa}$ coiled-coil protein dysbindin, was identified by using a yeast two-hybrid screen for interacting proteins with $\beta$-dystrobrevin as bait (Benson et al., 2001). It was hypothesized that dysbindin is an adaptor protein that links the DPC to an intracellular signaling cascade (Benson et al., 2001). In the brain, dysbindin immunoreactivity is localized to neurons (Benson et al., 2001). The potential importance of dysbindin is underlined by the recent demonstration of a link between mutations in dysbindin and familial schizophrenia (Straub et al., 2002; Schwab et al., 2003).

The neurological symptoms of patients with both muscular dystrophy and schizophrenia include ocular control abnormalities characteristic of cerebellar problems [muscular dystrophy (Liu et al., 2001; Anderson et al., 2002) and schizophrenia (Avila et al., 2002a,b)]. Therefore, we have studied the distribution of dysbindin in the normal mouse cerebellum and in the cerebellum of a murine model of Duchenne muscular dystrophy (the $m d x$ mouse) in which dystrophin is not expressed. The data reveal a striking and specific abnormality of the $m d x$ mouse: ectopic dysbindin immunoreactivity in mossy fiber afferents of the posterior cerebellar vermis. This region is important for ocular control, suggesting that cerebellar abnormalities may contribute to the neurological symptoms associated with human Duchenne muscular dystrophy, and also explain in part the link between dysbindin mutations and schizophrenia. 


\section{Materials and Methods}

Animals: perfusion and sectioning. Animal procedures conformed to institutional regulations and the Guide to the Care and Use of Experimental Animals from the Canadian Council of Animal Care. Normal adult CD1, $\mathrm{Balb} / \mathrm{c}$, and C57BL/6 mice (20-30 gm; $+/+$, no strain-specific differences noted) were obtained from Charles River Laboratories (St. Constant, Quebec, Canada), and C57BL/10ScSn-Dmd $d^{m d x} / \mathrm{J}$ hemizygous male $(m d x / \mathrm{Y})$ and homozygous female mutant mice $(m d x / m d x)$ were obtained from The Jackson Laboratory (Bar Harbor, ME) and maintained in the Animal Resource Centre at the University of Calgary. Mice were deeply anesthetized with an intraperitoneal injection of $100 \mathrm{mg} / \mathrm{kg}$ somnotol. The mice were then killed by transcardiac perfusion with an initial rinse using ice-cold $0.9 \%$ saline followed by either ice-cold Bouin's fixative or 4\% paraformaldehyde in PBS, pH 7.2 (Sigma, St. Louis, MO). The brains were removed and immersion-fixed for an additional $24 \mathrm{hr}$ at $4^{\circ} \mathrm{C}$. The cerebella were then cryoprotected through a series of buffered $10 \%$ ( $2 \mathrm{hr}$ ), 20\% (2 hr), and 30\% (overnight) sucrose solutions, serially sectioned in the transverse plane at $40 \mu \mathrm{m}$, and mounted on glass slides.

3-Acetylpyridine injections. Adult Balb/c mice $(n=6: 20-25 \mathrm{gm})$ were given an intraperitoneal injection of 3-acetylpyridine $(50 \mathrm{mg} / \mathrm{kg}$, i.p., diluted 1:100 in PBS; Sigma) and monitored closely for 3-5 hr after treatment for respiratory difficulties (control animals, $n=3$, were injected intraperitoneally with an equal volume of PBS). Animals were killed when ataxia became evident (7-11 d) and the cerebella were fixed and sectioned as described above. Two parallel series of sections were collected: one was stained for cresyl violet and the other processed for fluorescence anti-dysbindin/anti-calbindin double immunohistochemistry (see below).

Immunohistochemistry. All antibodies were diluted in 10\% normal goat serum in PBS. Mouse monoclonal anti-zebrin II was used directly from spent hybridoma culture medium diluted 1:1000 (Brochu et al., 1990); dysbindin was detected by using a rabbit polyclonal antibody (m10-TRX, 1:500; Benson et al., 2001); mouse monoclonal antisynaptophysin (1:100) and goat anti-choline acetyltransferase (1:100) were purchased from Chemicon (Temecula, CA); mouse monoclonal anti-calretinin (1:100) was obtained from BD PharMingen (Mississauga, Ontario, Canada); rabbit polyclonal anti-heat shock protein 25 (antiHSP25, 1:500) was purchased from StressGen (Victoria, British Columbia, Canada); mouse monoclonal anti-neuronal nitric oxide synthase (anti-nNOS, 1:100) and mouse monoclonal anti-actin (antibody C-11, 1:1000) were purchased from Santa Cruz Biotechnology (Santa Cruz, CA); mouse monoclonal anti-calbindin (1:500) was obtained from Swant (Bellinzona, Switzerland); rabbit polyclonal anti-synaptoporin (1: 500) was purchased from Synaptic Systems (Göttingen, Germany); rabbit polyclonal anti-cysteine string protein $(1: 10,000$; Braun and Scheller, 1995) was a gift of Dr. Jan Braun (University of Calgary).

Sections were rinsed three times in PBS for 5 min each, incubated in $30 \% \mathrm{H}_{2} \mathrm{O}_{2}$ for $10 \mathrm{~min}$ at room temperature, and again rinsed three times in PBS for $5 \mathrm{~min}$. Sections were then blocked in $10 \%$ normal goat serum in PBS for $2 \mathrm{hr}$ at room temperature. After blocking, sections were incubated overnight at room temperature in primary antibodies. After three 5 min rinses in PBS, sections were incubated in either HRP-conjugated goat anti-rabbit (diluted 1:200) or Vectastain Elite biotinylated rabbit IgG (1:300; Vector Laboratories, Burlingame, CA) as appropriate. Staining was visualized by incubation in $0.5 \mathrm{mg} / \mathrm{ml}$ diaminobenzidine (Sigma), $0.5 \mu \mathrm{l} / \mathrm{ml} 30 \% \mathrm{H}_{2} \mathrm{O}_{2}$ in PBS until the desired color intensity was achieved. Sections were then dehydrated and mounted in Entellan (EM Science, Gibbstown, NJ). For double labeling the tissue was incubated in both primary antibodies overnight at room temperature, rinsed, and then incubated for $2 \mathrm{hr}$ in a mixture of Alexa-546-conjugated goat antirabbit Ig (Molecular Probes, Eugene, OR) and cyanine 2 (Cy2)-conjugated donkey anti-mouse Ig (Jackson ImmunoResearch Laboratories, West Grove, PA), both diluted 1:1000. After several rinses in PBS, sections were coverslipped in nonfluorescing mounting medium (Fluorsave Reagent, Calbiochem, La Jolla, CA).

Photomicrographs were captured either with a PhotoMetrics (Huntington Beach, CA) Quantix digital camera running under V for Windows or a SPOT Cooled Color digital camera (Diagnostic Instruments,
Sterling Heights, MI). For confocal microscopy, an Olympus (Tokyo, Japan) Fluoview BX50 microscope was used and Z-stacked images (10 layers, each $2 \mu \mathrm{m}$ in depth) were captured by using Fluoview software. Montages were assembled in Adobe Photoshop (Adobe Systems, San Jose, CA). The images were cropped and corrected for brightness and contrast but not otherwise manipulated.

Western blotting. Western blot analysis of both wild-type and $m d x$ tissue was performed using a conventional protocol. Cerebellar homogenates were separated using PAGE according to Towbin et al. (1979). Gels were electroblotted onto nitrocellulose membranes and probed with anti-dysbindin. Antibody binding was detected using electrochemiluminescence (Amersham Biosciences, Baie d' Urfe, Quebec, Canada) peroxidase immunochemistry. Equal protein loadings were confirmed by detecting the level of actin on the blot.

\section{Results}

\section{Dysbindin expression in the mouse cerebellum}

Western blot analysis reveals that dysbindin is expressed at high levels in the mouse cerebellum (Fig. $1 \mathrm{~A}$ ). Consistent with previous data from whole brain (Benson et al., 2001), cerebellar dysbindin levels estimated from densitometric scans of Western blots are ninefold higher than those detected in homogenates from the tibialis anterior muscle. In addition, in about half of the samples a second, slightly smaller dysbindin-immunoreactive polypeptide appears on Western blots of cerebellar extracts (see Fig. $7 \mathrm{~A}$ for a counterexample); no equivalent was ever detected in muscle.

Peroxidase immunohistochemistry with anti-dysbindin heavily deposits peroxidase reaction product in punctate patches in the granular layer of the adult mouse cerebellum (Fig. $1 B, C, D)$. In addition, dysbindin-like immunoreactivity is seen at lower levels in Purkinje cell somata (Fig. $1 B$, arrowhead) and dendrites (Fig. $1 B$, arrow) in the molecular layer. The intensity of Purkinje cell immunoreactivity varies significantly between lobules (Fig. 1, compare $B$ and $D$ ). It is unclear whether differential immunoreactivity in the granular and Purkinje cell layers is attributable to differences in the level of expression or if it reflects the accessibility of the dysbindin epitope. Seen at high magnification, the granular layer staining is associated with mossy fiber synaptic glomeruli, a complex synaptic structure comprising a large mossy fiber presynaptic terminal, several postsynaptic granule cell dendrites, and inhibitory inputs from Golgi interneurons (Fig. 1E). To confirm that dysbindin immunoreactivity in the granular layer is associated with synapses, sections were doubleimmunofluorescence-stained for dysbindin and synaptophysin (Fig. $1 F$ ). Most mammalian CNS synapses are enriched in the 38 $\mathrm{kDa}$ synaptic vesicle protein synaptophysin (Wiedenmann and Franke, 1985; Leclerc et al., 1989; Fykse et al., 1993). In the granular layer of the cerebellum, strong synaptophysin immunoreactivity is detected in mossy fiber synaptic glomeruli (Fig. $1 F$, green). Dysbindin-synaptophysin double immunofluorescence staining confirms that all glomeruli immunoreactive for dysbindin also express synaptophysin (Fig. $1 F$, arrows), but dysbindin immunoreactivity is not detected in all synaptophysinimmunoreactive glomeruli (Fig. $1 F$, arrowheads).

\section{Granular layer heterogeneity}

Because dysbindin expression is restricted to a subset of mossy fiber glomeruli, we undertook a systematic analysis of their topography. Patterns of gene expression, afferent connectivity and cerebellar mutations affecting neonate and adult mice reveal a set of boundaries that divides the cerebellum into four transverse zones: the anterior zone (AZ; lobules I-V), the central zone (CZ; robules VI and VII), the posterior zone (PZ; lobules VIII and 

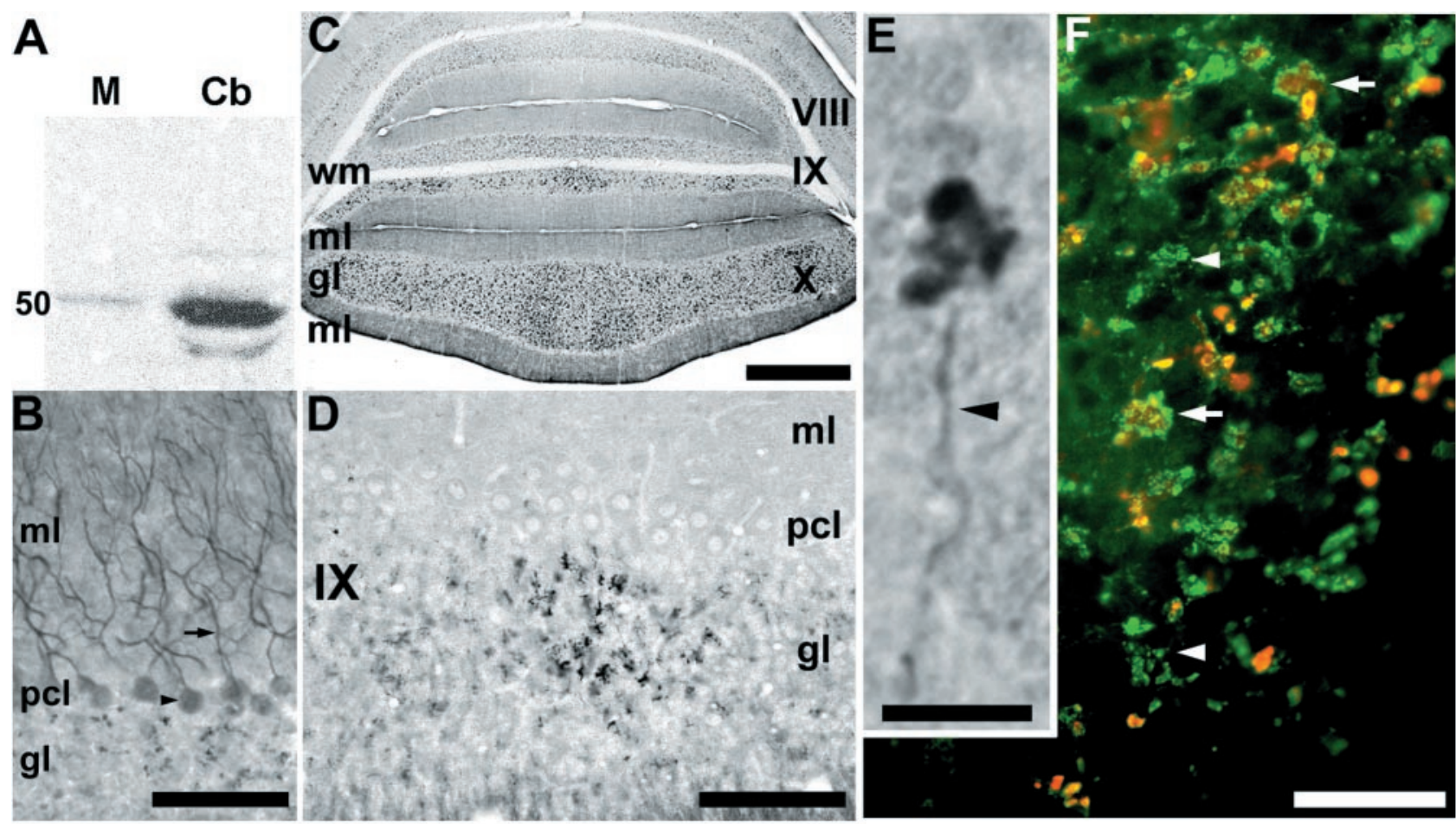

Figure 1. A, Western blot analysis of dysbindin in the cerebella of adult mice. Anti-dysbindin staining of an extract from adult mouse tibialis anterior (M) reveals a single immunoreactive band at an apparent molecular weight of $50 \mathrm{kDa}$. An anti-dysbindin immunoreactive protein running at the same apparent molecular weight is detected in the cerebellum ( $\mathrm{Cb}$ ) at levels ninefold higher than those found in muscle. In addition, a second, weaker, lower apparent molecular weight band is seen irregularly in the cerebellar extract, that is never detected in muscle. $B$, Immunoperoxidase staining of a transverse section through the hemispheres with anti-dysbindin shows dysbindin immunoreactivity in the somata (arrowhead) and dendrites (arrow) of Purkinje cells. gl, Granular layer; $\mathrm{ml}$, molecular layer, $\mathrm{pcl}$, Purkinje cell layer. C, Transverse section through the posterior lobe vermis (lobules VIII-X) immunoperoxidase stained with anti-dysbindin. Reaction product is deposited uniformly in the molecular layer $(\mathrm{ml})$ and as clusters of immunoreactive punctae in the granular layer. There is no staining of the white-matter tracts (wm). D, Immunoperoxidase staining of a transverse section through lobule IX of the cerebellar vermis with anti-dysbindin shows heterogeneous dysbindin immunoreactivity in the granular layer, with a cluster of immunoreactive mossy fiber terminals flanked by regions of granular layer with little or no reaction product. Staining is weak in the Purkinje cell layer and molecular layer. E, Dysbindin immunoreactivity in the granular layer is associated with large mossy fiber synaptic glomeruli. Occasionally, axon-like processes are observed (arrowhead), terminating in prominent synaptic rosettes. F, Double immunofluorescence staining of lobule IX for synaptophysin (green) and dysbindin (red) shows that dysbindin co-localizes with a subset of synaptophysin immunoreactive terminals (orange) in the granular layer (synaptophysin-positive/dysbindin-negative synapses are green). Scale bars: $A, B, D, 100 \mu \mathrm{m} ; C, 500 \mu \mathrm{m} ; E, 10 \mu \mathrm{m} ; F, 50 \mu \mathrm{m}$.

IX), and the nodular zone (NZ; lobules IX-X) (Hawkes and Eisenman, 1997; Ozol et al., 1999; for review, see Armstrong and Hawkes, 2000). The distribution of dysbindin-immunoreactive mossy fiber terminals is different between each transverse zone. When viewed in transverse sections, dysbindin-immunoreactive synaptic glomeruli in the AZ (Fig. 2A) and the NZ (Fig. 2C) form a symmetrical array of parasagittal clusters. Similar clusters are not evident in the granular layer of the CZ (Fig. $2 B$ ), where glomeruli are sparse, or of the PZ, where glomeruli are plentiful but distributed homogeneously (not shown). In the AZ, dysbindin-immunoreactive glomeruli are scattered thinly throughout and are clustered into at least five parasagittal stripes interrupted by stripes in which antidysbindin labeled glomeruli are sparse (Figs. 2A, 3A, 7E). A long thin stripe of glomeruli straddles the anatomical midline of the cerebellum and can be traced through all five lobules of the AZ. Two additional stripes lie on either side of the midline: one centered $\sim 500 \mu \mathrm{m}$ from the midline, and another more lateral, with its medial edge $\sim 750 \mu \mathrm{m}$ from the midline and extending to the lateral edges of the anterior vermis. Moving caudally into the $\mathrm{CZ}$ (Fig. 2 B), few dysbindin-immunoreactive glomeruli are present in lobules VI and VII. Numerous weakly immunoreactive glomeruli are found in the $\mathrm{PZ}$, but it is not until the ventral aspect of lobule VIII (PZ/NZ boundary) that poorly defined stripes are seen again. As in the AZ, at least five stripes can be identified in the NZ (Figs. 2C, 3B). A dense cluster of glomeruli straddles the midline of lobules VIII and IX and extends caudally to the dorsal aspect of lobule X. Approximately $650 \mu \mathrm{m}$ lateral to the midline are two symmetrical immunoreactive clusters. More laterally still, with medial edges roughly $1 \mathrm{~mm}$ from the midline, is a third pair of ill-defined clusters that extend to the edges of the lobule. In the posterolateral fissure between lobules IX and X (the boundary between the $\mathrm{PZ}$ and the NZ) the pattern again changes. In the NZ the midline is mostly immunonegative, with a pair of broad reactive bands astride the midline. More laterally, many glomeruli are stained but no clusters can be defined.

To relate the topography of the dysbindin-immunoreactive mossy fiber terminal fields to the better-understood Purkinje cell compartmentation, we have compared the stripes of dysbindin immunoreactive mossy fiber synaptic glomeruli to the parasagittal stripes of Purkinje cells, as revealed by two adult stripe markers, zebrin II/aldolase C (Brochu et al., 1990; Ahn et al., 1994) and HSP25 (Armstrong et al., 2000). In the AZ and PZ, zebrin II is expressed in a specific population of Purkinje cells that form a parasagittal array of stripes $\left(\mathrm{P}^{+}\right)$interrupted by a second population of Purkinje cells that are immunonegative for zebrin II $\left(\mathrm{P}^{-}\right)$(for review, see Armstrong and Hawkes, 2000). Sections double-immunofluorescence-stained for zebrin II and dysbindin reveal that dysbindin-immunoreactive glomerular clusters align with the zebrin II-immunoreactive stripes in the AZ (Fig. 4A), although the $\mathrm{P} 1{ }^{+}$and $\mathrm{P} 2{ }^{+}$zebrin II stripes are consistently narrower than the underlying mossy fiber clusters (Fig. 4A). The PZ has zebrin II $(+/-)$ stripes of roughly equal widths (e.g., lobule 

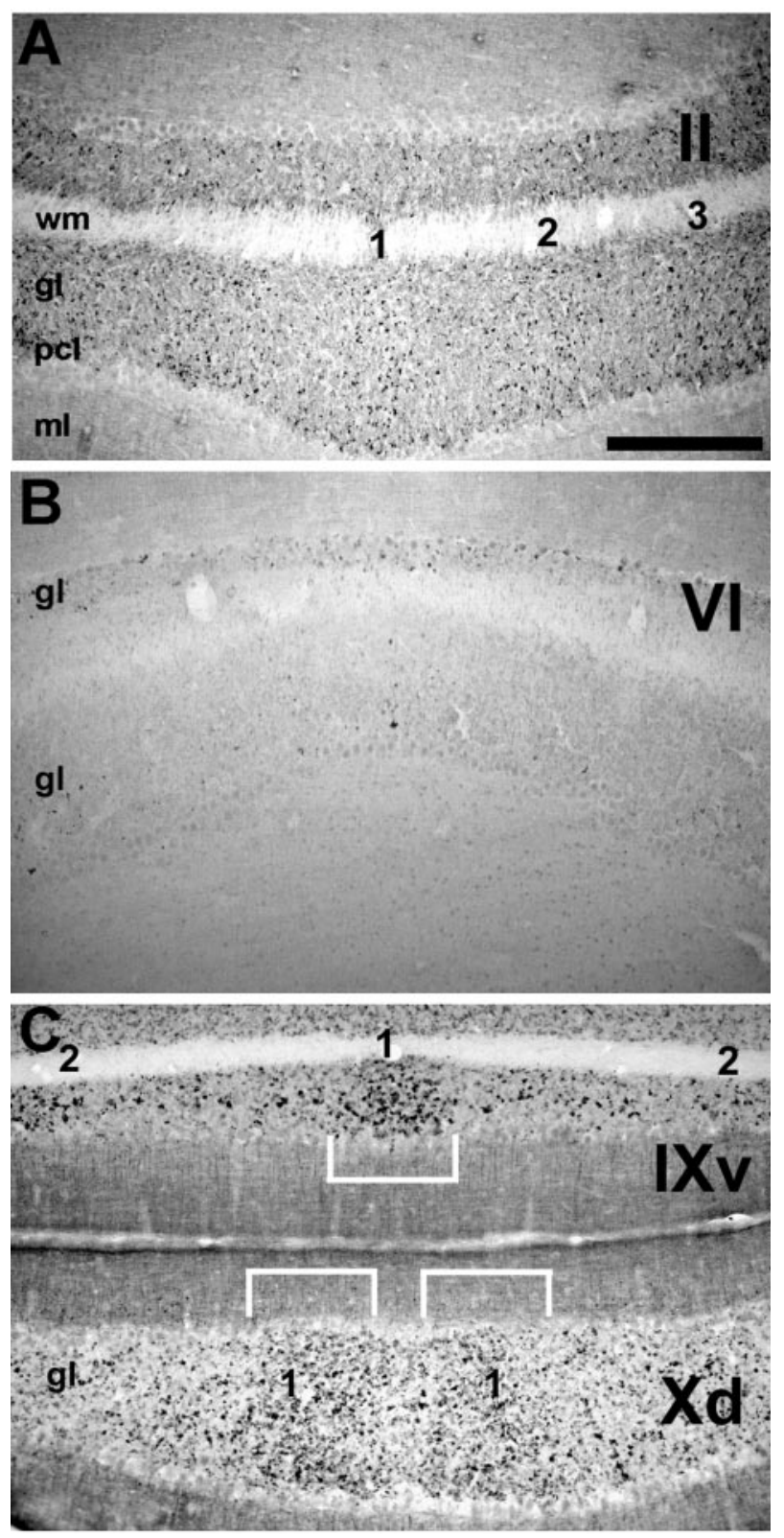

Figure 2. Transverse sections through the vermis immunoperoxidase stained for dysbindin show numerous mossy fiber synaptic glomeruli in the granular layer of lobule Il $(A)$, few present in lobule $\mathrm{VI}(B)$, and heavy labeling in lobule $X(C)$. In the AZ and the NZ, dysbindinimmunoreactive glomeruli are distributed heterogeneously to form clusters (numbered 1-3: numbering is specific to individual transverse zones, and there is no reason to assume that stripes are contiguous across transverse zone boundaries). In C, the white brackets outline cluster 1 in ventral lobule IX and dorsal lobule X. pcl, Purkinje cell layer. Scale bar, $250 \mu \mathrm{m}$.

VIII; Eisenman and Hawkes, 1993), but no reproducible striped pattern was detected for dysbindin; rather, dysbindinimmunoreactive terminals are distributed homogeneously throughout the granular layer. In the CZ and NZ, all Purkinje cells are anti-zebrin II-immunoreactive, but Purkinje cell stripes can be revealed by the constitutive expression of HSP25 (Armstrong et al., 2000). In the NZ, the stripes of dysbindinimmunoreactive mossy fiber glomeruli are centered on the stripes of Purkinje cells that express HSP25 (but again, the glomerular stripes are consistently wider than the Purkinje cell stripes) (Fig. $4 B$ ).

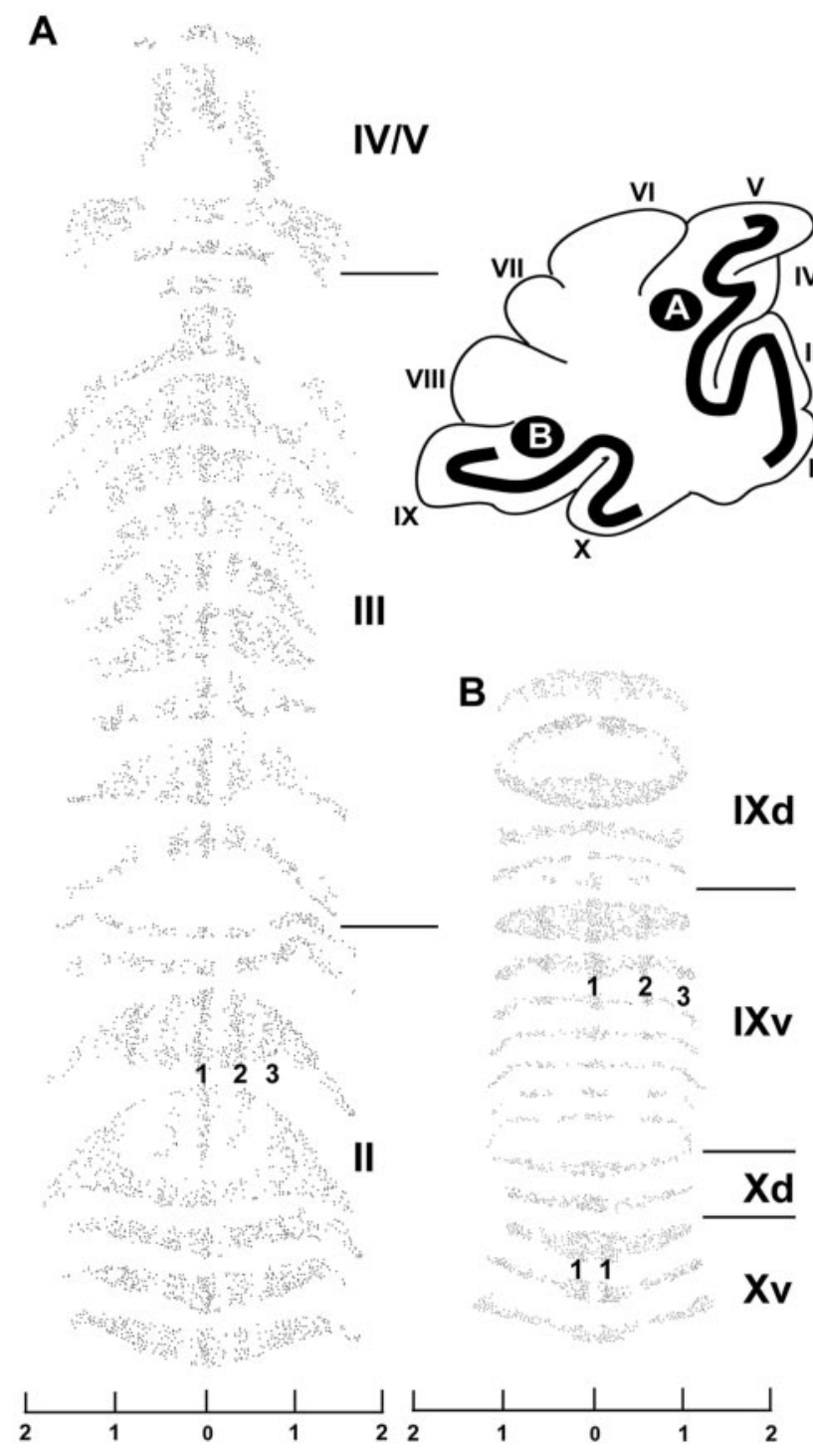

Figure 3. A, Dysbindin immunoreactive profiles in the granular layer of the AZ (lobules II-V) terminate in parasagittal stripes. Immunolabeled mossy fiber glomeruli in the granular layer of the AZ (lobules II-V) were plotted from every second $40 \mu \mathrm{m}$ section through the vermis (for additional details, see 0zol et al., 1999). The region flattened in this way is indicated on the diagrammatic sagittal view (Roman numerals refer to lobules). The flattened view reveals that the glomerular clusters seen in transverse sections form long parasagittal stripes, one at the midline (1), and two bilaterally: the first (2) centered $\sim 500 \mu \mathrm{m}$ from the midline, the other (3) with its medial edge $\sim 750 \mu \mathrm{m}$ from the midline and extending laterally to the edge of the vermis. B, Mossy fiber glomerular clusters in the granular layer of the NZ (lobules IX-X) form long parasagittal stripes in lobule IX, one at the midline (1), and two bilaterally: one (2) centered $\sim 500 \mu \mathrm{m}$ from the midline, the other (3) with its medial edge $\sim 750 \mu \mathrm{m}$ from the midline and extending laterally to the edge of the vermis. In the dorsal aspect of lobule $X$, the pattern changes to one in which the midline stripe has few immunoreactive glomeruli, there is a prominent band laterally on either side (1); more laterally no clear compartmentation is evident. The scales are in millimeters.

Granular layer heterogeneity: dysbindin immunoreactivity is associated with synapses on unipolar brush cells

Previous studies of mossy fiber chemical heterogeneity in the cerebellum suggest two plausible identities for some of the dysbindin-immunoreactive glomeruli: the mossy fiber projections immunoreactive for choline acetyltransferase (ChAT) (Barmack et al., 1992a,b,c), and those that terminate on unipolar brush cells (for review, see Jaarsma et al., 1997; Mugnaini et al., 1997; Dino et al., 2000). 

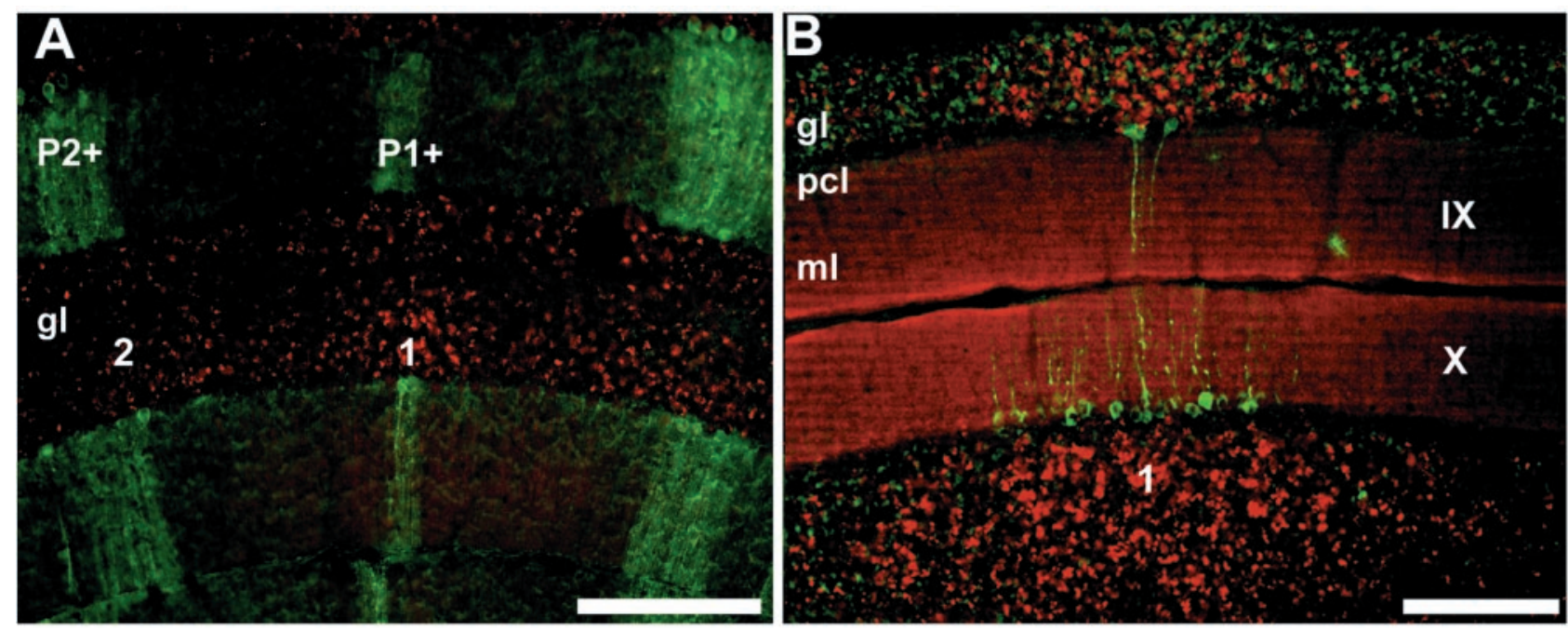

Figure 4. Parasagittal clusters of dysbindin-immunoreactive mossy fiber terminals bear a consistent relationship to the overlying Purkinje cell compartmentation. $A$, Doubleimmunofluorescence staining with anti-dysbindin (red) and anti-zebrin II (green) in the lobule V of the cerebellar vermis. The Purkinje cell stripes $\mathrm{P1}{ }^{+}$and $\mathrm{P2}^{+}$are labeled: the midline cluster of dysbindin-immunoreactive terminals (1) in the granular layer is centered beneath $\mathrm{P}^{+}{ }^{+}$and the first lateral cluster (2) beneath $\mathrm{P2}{ }^{+}$. B, Because both anti-dysbindin and anti-HSP25 were raised in rabbit, serial $40 \mu \mathrm{m}$ transverse sections through the NZ (lobules IX and X) were each immunostained with a single antibody and the digital images overlaid (dysbindin, red; HSP25, green). The midline HSP25-immunoreactive stripe is shown (for details of constitutive HSP25 expression in the mouse NZ, see Armstrong et al., 2000): the medial dysbindin-immunoreactive mossy fiber terminal field stripe (1) underlies the HSP25-immunoreactive stripe, but extends beyond it laterally to either side. Scale bars: $A, 250 \mu \mathrm{m} ; B, 100 \mu \mathrm{m}$.

Transverse sections through the adult mouse cerebellum were double-immunofluorescence-stained for dysbindin and ChAT (Fig. 5A). Large ChAT-immunoreactive mossy fiber rosettes in the granule cell layer are restricted primarily, but not exclusively, to the NZ (Fig. 5A). A similar distribution was described previously in rabbits (Barmack et al., 1992a,b, c). Double immunofluorescence with anti-dysbindin and anti-ChAT localizes ChAT immunoreactive glomeruli to the same stripes as those revealed by using anti-dysbindin (Fig. 5A). However, within the individual clusters few of the glomeruli in any one section are double-labeled, suggesting that dysbindin and ChAT are primarily expressed by distinct glomerular subsets with a common topography.

Unipolar brush cells can be identified by using anti-calretinin immunocytochemistry (Dino et al., 1999) (Fig. 5B). Based on the expression of calretinin and the morphology of the immunoreactive neurons, parasagittal stripes of unipolar brush cells can be identified in lobules IX and X of the mouse cerebellum, with the same topography as the anti-dysbindin immunoreactive terminals: dysbindin-calretinin double immunofluorescence confirms that almost all dysbindin-immunoreactive glomeruli are associated with calretinin-immunoreactive unipolar brush cells, and within a stripe of calretinin-immunoreactive profiles, $>90 \%$ were double-labeled with anti-dysbindin (Fig. $5 C$ ). The dendritic brushes of unipolar brush cells (Fig. 5D, arrow) were frequently seen to associate intimately with dysbindin immunoreactive glomeruli (Fig. 5D, asterisk), with the dendritic tree of the unipolar brush cell wrapped around a strongly dysbindinimmunoreactive glomerulus. Indeed, it is possible that some terminals immunoreactive for both antigens are internal mossy fibers originating from unipolar brush cells (Nunzi and Mugnaini, 2000; Nunzi et al., 2002); however, the somata of unipolar brush cells never express dysbindin.

Finally, nNOS histochemistry has revealed a complex heterogeneity in the granular layer (Yan et al., 1993; Hawkes and Turner, 1994; Schilling et al., 1994; for review, see Oberdick et al., 1998), and nNOS has been shown to be a part of the DPC cytoplasmic complex in muscle through its binding to syntrophin
(Brenman et al., 1995).Therefore, dysbindin-nNOS double immunofluorescence was used to compare the two distributions. In the granular layer, nNOS immunoreactivity reveals a complex mosaic of high-, low-, and non-reactive patches (Fig. 5E). Dysbindin-immunoreactive glomerular clusters and patches of nNOS expression tend to be complementary, such that high levels of dysbindin immunoreactivity are typically in patches of low nNOS expression. However, the topography is not clear-cut, and dysbindin-immunoreactive terminals are often seen within the high-nNOS patches (Fig. 5E-G).

\section{Dysbindin immunoreactivity in Purkinje cell dendrites does not require climbing fiber input}

In addition to strong dysbindin immunoreactivity in a subset of mossy fiber synaptic glomeruli, the Purkinje cell somata are usually lightly stained with anti-dysbindin and weak, patchy staining of the cerebellar molecular layer, in particular on the primary shafts of Purkinje cell dendrites, is also seen in most regions of the cerebellar cortex (Fig. 6A). Little or no reaction product was deposited in the secondary dendrites or dendritic spines. If dysbindin is associated with synapses on Purkinje cells then, based on its localization to the smooth primary dendrites, it seems likely that either it is located presynaptically in the climbing fiber terminals or postsynaptically in the dendritic shafts. To differentiate between these possibilities, a single dose of 3-acetylpyridine was used to cause the degeneration of the inferior olivary complex, and thus the climbing fiber afferent projection [rat (Desclin and Colin, 1980) and mouse (Armstrong et al., 2001)]. Between 7 and $11 \mathrm{~d}$ after treatment, mice developed ataxic limb movements, and histological examination of cresyl violet-stained sections revealed that most neurons in the inferior olives had degenerated (Fig. $6 B, C$ ). In contrast, dysbindin immunoreactivity in Purkinje cell dendrites was unchanged by climbing fiber deafferentation (Fig. 6D), suggesting that dysbindin is postsynaptic (associated with Purkinje cell dendrites) rather than presynaptic in the climbing fiber terminals. In rats, climbing fiber deafferentation after the administration of 3-acetylpyridine was followed by the 

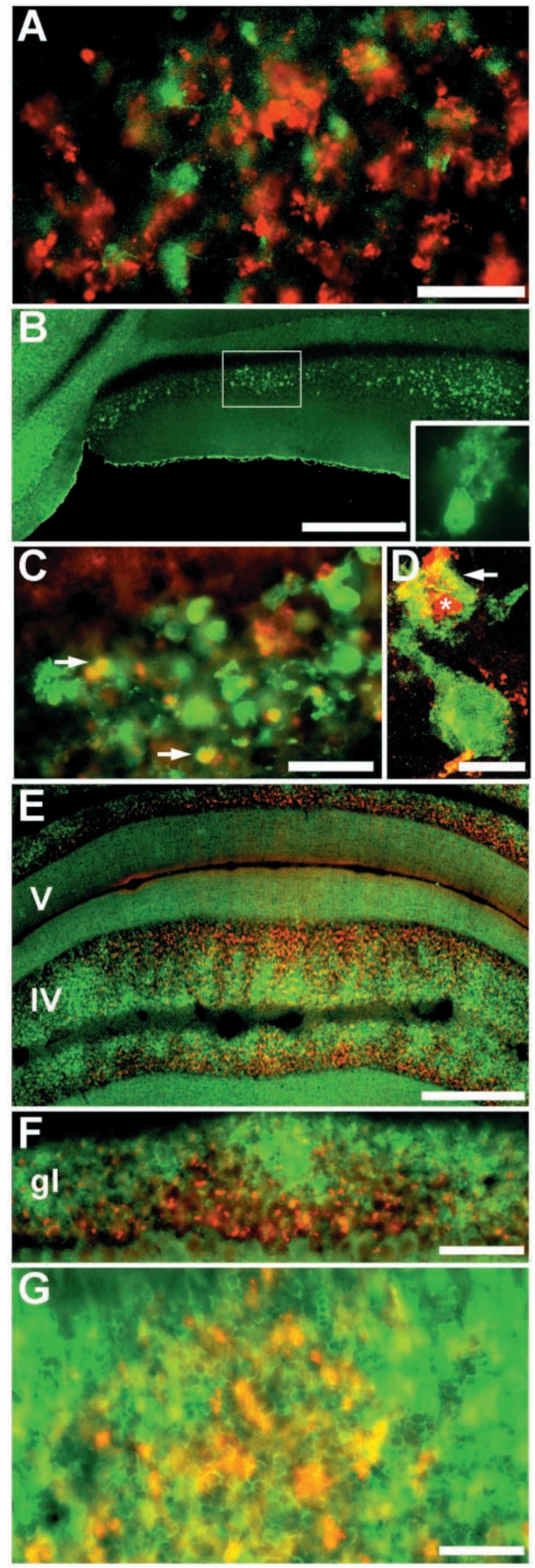

clearing of climbing fiber debris from the molecular layer within $3 \mathrm{~d}$ of treatment (Desclin, 1976). Therefore, in our model, the persistence of dysbindin immunoreactivity in climbing fiber terminal debris can be ruled out because mice were allowed to survive for at least $7 \mathrm{~d}$ after treatment.

\section{Dysbindin expression in the cerebellum of $\mathbf{m d x}$ mice}

In brain, dysbindin is associated with the dystrobrevins as part of a dystrophin-associated protein complex (Blake et al., 1999). Therefore, we have looked at cerebellar dysbindin expression in a mouse model for Duchenne muscular dystrophy, the $m d x$ mutant, in which dystrophin is absent. It has been shown previously that in $m d x$ muscle, dysbindin immunoreactivity is increased at the sarcolemma (Benson et al., 2001). To determine whether the same is true in the cerebellum, Western blots of cerebella extracts from $m d x(m d x / m d x$ female and $m d x / Y$ male $)$ mice and $+/+$ littermates were probed with anti-dysbindin. No consistent upregulation of dysbindin expression was identified (Fig. 7A, inset). However, when transverse sections of normal $(+/+)$ and $m d x$ mice were immunostained with anti-dysbindin and compared, a striking difference was observed: in lobules IX-X (NZ) of $m d x$ mice, many more glomeruli are immunoreactive, and the parasagittally oriented clusters of dysbindin-immunoreactive glomeruli are replaced by a homogenous pattern in which low density stripes in the granular layer of the $+/+$ mouse (Fig. 7A,C) are filled with immunoreactive glomeruli in $m d x$ (Fig. $7 B, D$ ). Relative numbers of mossy fiber glomeruli were estimated from serial sections through the dorsal aspect of the lobule IX of the vermis, immunoperoxidase-stained for anti-dysbindin (three $+/+$ controls and three $m d x / m d x$ mutants; dysbindin immunoreactive glomeruli from three $40 \mu \mathrm{m}$ thick transverse sections were counted per individual; $1.25 \mathrm{~mm}$ of granular layer was counted on either side of the midline. The numbers are not stereologically corrected. There is a more than threefold increase in dysbindin-immunoreactive glomeruli in the lobule IX of $m d x$ $(333 \pm 20.8$ glomeruli per millimeter width per section in $m d x$; $96 \pm 8.8$ in $+/+; p<3.5 \times 10^{-39}$; ANOVA). Histograms generated by counting profiles immunoreactive for dysbindin in matched sections from $m d x$ and $+/+$ mice confirm the differences in staining pattern: in $m d x$, not only are the spaces between clusters now densely filled with stained glomeruli but in addition, the regions in $+/+$ animals that are relatively highly reactive are also more densely populated with reactive terminals in $m d x$ cerebella (Fig. 7E). Similar increases in dysbindin-immunoreactive

\section{$\leftarrow$}

Figure 5. Heterogeneity of the granular layer. $A$, transverse section through lobule $X$ doubleimmunofluorescence-labeled for dysbindin (red) and ChAT (green). The first lateral cluster is shown (see Figs. 2C, 3B). Double-labeled profiles are rare, implying that mossy fiber terminals immunoreactive for ChAT constitute a separate population from those that stain with antidysbindin. $B$, Calretinin immunoreactivity reveals parasagittally oriented clusters of unipolar brush cells. A high-power view of a single unipolar brush cell is shown in the inset. C, Highmagnification view of the granular layer showing profiles immunoreactive for calretinin alone, and for both calretinin and dysbindin. D, Confocal image of a single unipolar brush cell suggests that profiles immunoreactive for calretinin alone are primarily unipolar brush cell somata, and profiles immunoreactive for both calretinin and dysbindin are primarily unipolar brush cell dendrites (arrow) associated tightly with mossy fiber terminals (asterisk). E, F, G, Transverse sections through the vermis double-immunofluorescence-stained for nNOS (green) and dysbindin (red). The expression patterns of dysbindin and nNOS are primarily complementary. nNOS immunoreactivity in lobule IV is homogeneous in the molecular layer but highly heterogeneous in the granular layer, in which it is preferentially found in the deeper half, closer to the white matter, in which it is restricted to a complex array of patches. In contrast, dysbindin immunoreactivity is heaviest nearer the Purkinje cell layer. Scale bars: $A, 50 \mu \mathrm{m} ; B, 250 \mu \mathrm{m}$ (inset, $50 \mu \mathrm{m}$ );C, $50 \mu \mathrm{m} ; D, 10 \mu \mathrm{m} ; E, 250 \mu \mathrm{m} ; F, 100 \mu \mathrm{m} ; G, 50 \mu \mathrm{m}$. 


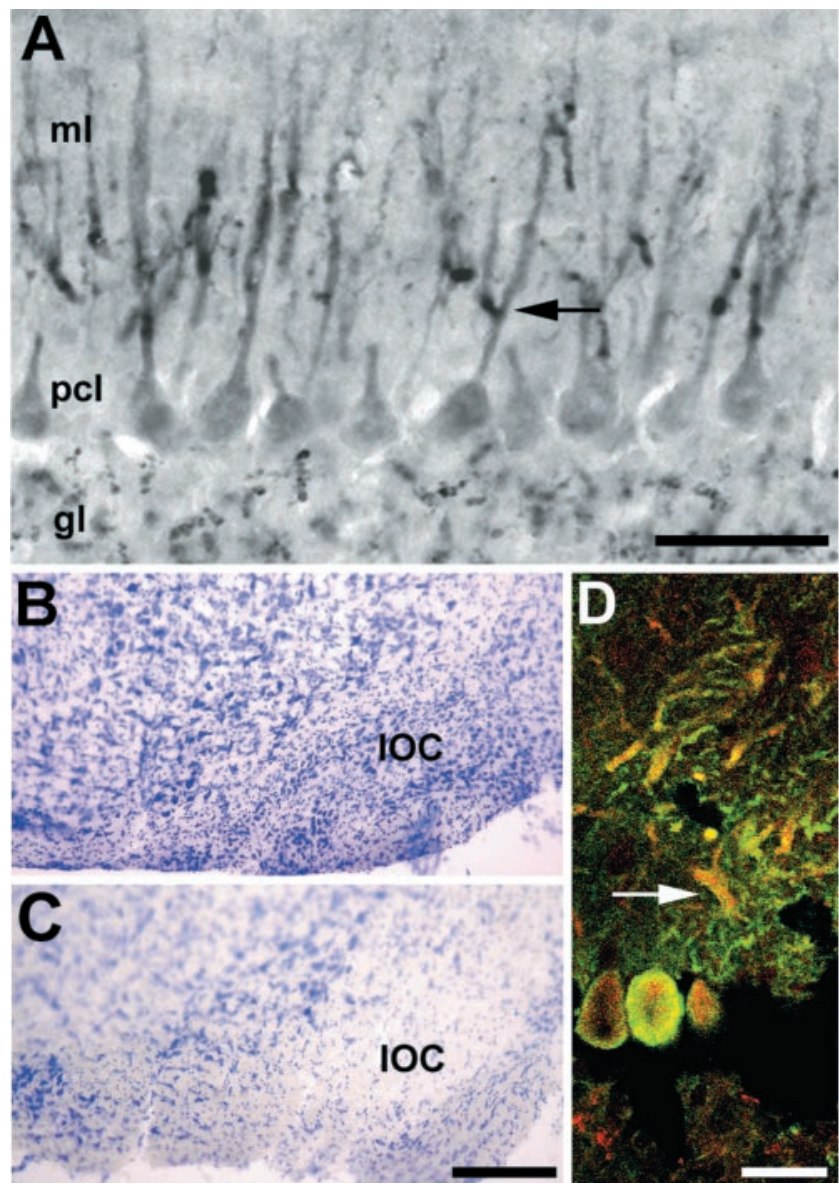

Figure 6. A, Dysbindin immunoreactivity is associated with Purkinje cell dendrites. Transverse section through the cerebellar vermis immunoperoxidase stained with anti-dysbindin. Reaction product is deposited in mossy fiber synaptic glomeruli in the granular layer, lightly in the Purkinje cell somata in the Purkinje cell layer, and intensely as punctae along the Purkinje cell primary dendritic shafts and their initial branch points in the molecular layer (arrow). There is little or no immunoreactivity in the secondary and tertiary dendrites or the dendritic spines. $B$, C, Climbing fiber afferents are not necessary to maintain dysbindin expression in the molecular layer. Cresyl violet-stained sections through the medulla oblongata of control mice ( $B$ ) showing the inferior olivary complex (IOC) and a 3-acetylpyridine-treated animal $(C) 11 \mathrm{~d}$ after injection showing the almost complete ablation of the inferior olivary complex. D, Confocal microscopic analysis of a section from a 3-acetylpyridine-treated mouse doubleimmunofluorescence-stained for the Purkinje-cell-specific protein calbindin (green) and dysbindin (red). Purkinje cell bodies and primary dendrites remain immunoreactive for both antigens (arrow), despite the ablation of climbing fiber innervation. Scale bars: $A, 100 \mu \mathrm{m} ; B, C$ (in C), $250 \mu \mathrm{m} ; \mathrm{D}, 20 \mu \mathrm{m}$.

terminals were not observed in other regions of the vermis, or in the hemispheres (data not shown).

The loss of well-defined stripes of dysbindin-immunoreactive mossy fiber terminals in the NZ of $m d x$ mice does not extend to other aspects of cerebellar compartmentation. First, the expression of zebrin II in $m d x$ mice is entirely normal (compare Figs. $8 \mathrm{~A}$ and $8 B$ ). Thus, the absence of dystrophin from the Purkinje cell dendrites does not affect the development of Purkinje cell compartmentation, and the ectopic dysbindin expression by mossy fiber glomeruli is not secondary to abnormal Purkinje cell compartmentation. The same is true for nNOS expression (data not shown). Secondly, the distribution of calretinin immunoreactivity is unchanged (compare Figs. $8 C$ and $8 D$ ): parasagittal clusters of calretinin immunoreactive unipolar brush cells are clear in the $m d x$ cerebellum, although glomeruli enriched with dysbindin are homogeneously distributed (and dysbindin-immunoreactive projections by far outnumber the available unipolar brush cell targets in $m d x$ ). Thus, ectopic dysbindin expression in mossy fiber glomeruli is not secondary to ectopia of the unipolar brush cells. To address the question of whether the additional antidysbindin immunoreactive mossy fiber terminals in $m d x$ reflect a general increase in the number of synapses, we have used peroxidase immunocytochemistry to compare several other proteins associated with mossy fiber presynaptic terminals: ChAT (Barmack et al., 1992a,b,c) (Fig. 8 E,F); synaptophysin (Wiedenmann and Franke, 1985; Leclerc et al., 1989; Fykse et al., 1993) (Fig. 8G,H); synaptoporin (Fykse et al., 1993) (Fig. 8I,J); and cysteine string protein (Braun and Scheller, 1995; Kohan et al., 1995) (Fig. $8 K, L)$. In no case was a significant difference observed between $+/+$ and $m d x$ cerebella $(n=3)$.

\section{Discussion}

The parasagittal mossy fiber terminal fields revealed by antidysbindin staining are consistent with much that is known about cerebellar anatomy. The striped organization of the cerebellum is best understood from the perspective of Purkinje cell heterogeneity (Herrup and Kuemerle, 1997; Oberdick et al., 1998; Armstrong and Hawkes, 2000), but the granular layer of the cerebellum is also both anatomically and biochemically heterogeneous (for review, see Ozol and Hawkes, 1997). For example, granular layer heterogeneity is revealed in the expression patterns of acetylcholinesterase (Marani and Voogd, 1977; Boegman et al., 1988), cytochrome oxidase (Hess and Voogd 1986; Leclerc et al., 1990), and nNOS (Yan et al., 1993; Hawkes and Turner, 1994; Schilling et al., 1994). Similarly, granular layer heterogeneity is also seen in the distribution of unipolar brush cells (Mugnaini and Floris, 1994). Most pertinently here, several mossy fiber afferent projections terminate in parasagittal stripes [e.g., cholinergic terminals originating from the medial vestibular nucleus (Barmack et al., 1992a,b; Jaarsma et al., 1997), spinocerebellar mossy fibers (Gravel and Hawkes, 1990; Ji and Hawkes, 1994), and cuneocerebellar mossy fibers (Ji and Hawkes, 1994; Serapide et al., 1994)]. Thus, the restriction of dysbindin immunoreactivity to a subset of synaptic glomeruli implies an association with one specific mossy fiber pathway or more. The arrangement of dysbindin-immunoreactive terminals in the $\mathrm{AZ}$ is different from both the spinocerebellar and cuneocerebellar projections [mouse (Akintunde and Eisenman, 1994) and rat (Ji and Hawkes, 1994; for review, see Ozol and Hawkes, 1997)], both of which terminate in stripes but with a different topographical relationship to the overlying Purkinje cell layer.

The distribution of dysbindin-immunoreactive mossy fiber glomeruli in the NZ of the vermis resembles both ChAT immunoreactivity and the distribution of unipolar brush cells (Dino et al., 1999). The distribution of dysbindin immunoreactivity in other areas of the brain also resembles that of ChAT (e.g., the dorsal cochlear nucleus and the hippocampus; Benson et al., 2001). It has been shown that unipolar brush cells are targets of ChAT-immunoreactive mossy fiber terminals (Jaarsma et al., 1996, 1997). However, anti-dysbindin and anti-ChAT immunoreactivities do not colocalize to the same glomeruli, suggesting that at least two mossy fiber afferent systems converge on the excitatory unipolar brush cell pathway in the NZ. The data are supported by previous work that showed ChAT-positive mossy fibers in the rat cerebellum account for only $20 \%$ of the afferent input to calretinin-immunoreactive unipolar brush cells (Jaarsma et al., 1996). It seems plausible then that dysbindinimmunoreactive mossy fibers partially account for the remaining $80 \%$ and innervate a subset of unipolar brush cells that are not 

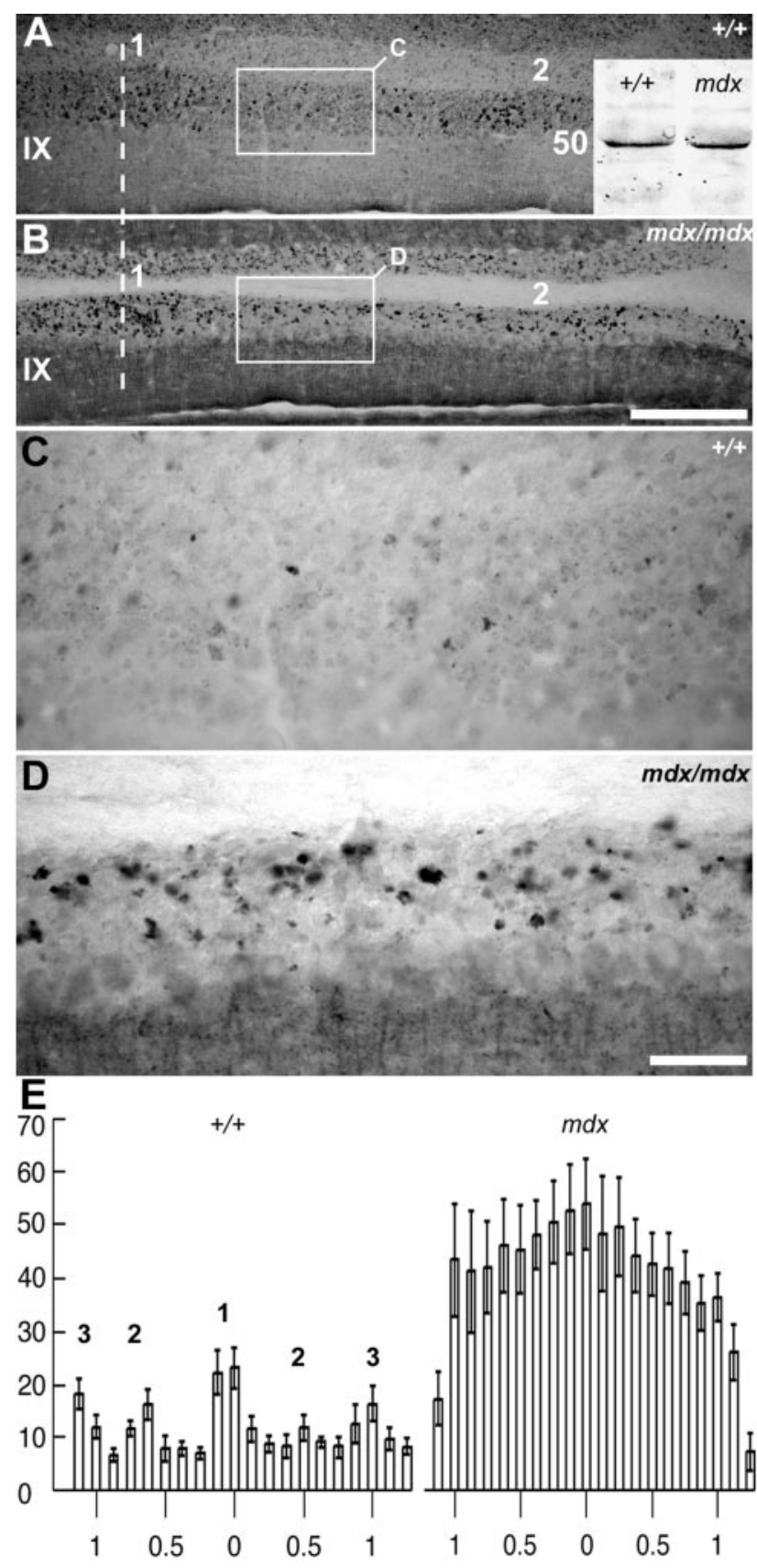

Figure 7. Dysbindin expression is abnormal in mossy fiber synaptic glomeruli of the $m d x$ mouse cerebellum. $A, B$, Immunoperoxidase-stained transverse sections through lobule IX of the control $(A,+/+)$ and dystrophic $(B, m d x)$ mice. The dashed line indicates the midline. The 1 and 2 clusters of dysbindin-immunoreactive glomeruli are labeled in $A$. The same clusters are difficult to discern in the $m d x$ mouse $(B)$ because the intervening granular layer now has numerous immunoreactive profiles $(B)$. $A$, inset, Western blot analysis comparing dysbindin expression in protein extracts from the cerebella of $m d x$ mice versus wild-type littermates. In both the $+/+$ and $m d x$, a prominent band was detected at $\sim 50 \mathrm{kDa}$ : densitometric scanning revealed no significant difference between the two (the lower-molecular-weight antigen seen in Fig. 1 was not detected in this sample). C, D, The regions of granular layer outlined by the rectangles in $A$ and $B$, showing ectopic dysbindin immunoreactivity in the $m d x$ mouse. $E$, Histograms illustrating the number of glomeruli in six individuals: three $m d x$ and three $+/+$ (control littermates). The bins represent the mean \pm SE numbers of dysbindin immunoreactive profiles from three $40 \mu \mathrm{m}$ transverse sections from each individual, taken from ventral lobule IX immunoperoxidase stained with anti-dysbindin. The scale is in millimeters. There is a more than threefold increase in the number of immunoreactive glomeruli in $m d x$. Furthermore, in $+/+$, at least five parasagittal clusters are evident $(1$, at the midline; 2 and 3 , laterally to either side), whereas in $m d x$, distinct clusters are obscured. Scale bars: $A, B$ (in $B$ ), 250 $\mu \mathrm{m} ; C, D$ (in $D), 50 \mu \mathrm{m}$.
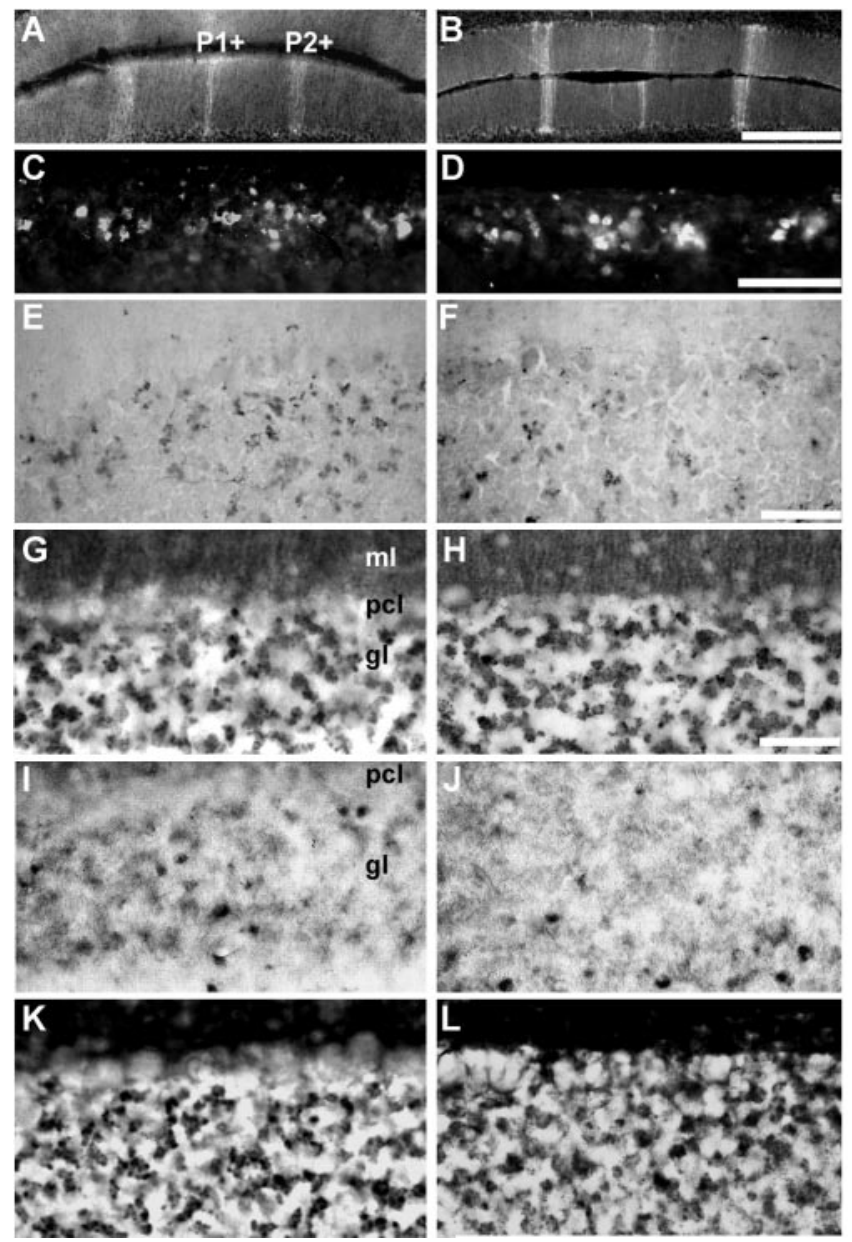

Figure 8. Many aspects of cerebellar patterning are unaffected in the $m d x$ mouse. $A, C, E, G$, $I, K,+I+; B, D, F, H, J, L, m d x . A, B$, Transverse sections through lobule III (AZ) immunofluorescence stained for zebrin II. The $\mathrm{P}^{+}{ }^{+}$and $\mathrm{P} 2^{+}$stripes are distinct in both. $C, D$, Transverse section through lobule IX immunofluorescence stained for calretinin. Roughly equal numbers of reactive profiles (predominantly unipolar brush cells) are stained in both. $E$, $F$, Transverse section through lobule IX immunoperoxidase-stained for ChAT. The number of mossy fiber glomeruli immunoreactive for ChAT in $m d x$ mice is unchanged. Three proteins associated with mossy fiber presynaptic terminals were also compared in immunoperoxidase-stained transverse sections through lobule IX: synaptophysin $(G, H)$, synaptoporin $(I, J)$, and cysteine string protein $(K, L)$. No systematic differences were seen between $+/+$ and $m d x$. Scale bars: $A, B$ (in $B$ ), $500 \mu \mathrm{m}$; $C, D$ (in $D), 250 \mu \mathrm{m} ; E, F$ (in $F$ ), $100 \mu \mathrm{m}$; $G-L$ (in $H$ ), $50 \mu \mathrm{m}$.

associated with any cholinergic pathways (e.g., the metabotropic glutamate receptor $1 \alpha$-immunoreactive subset of unipolar brush cells; Nunzi et al., 2002).

Dysbindin binds both $\alpha$ - and $\beta$-dystrobrevins; in muscle it physically interacts with dystrobrevin as part of a complex with dystrophin (Benson et al., 2001). $\beta$-Dystrobrevin is also associated with synapse-enriched fractions from the brain (Blake et al., 1999), and in the cerebellum, $\beta$-dystrobrevin immunoreactivity is found in granule cells (i.e., the postsynaptic site in the mossy fiber synaptic glomeruli) and in Purkinje cells. Therefore, it seems likely that in the cerebellum in vivo, dysbindin binds to $\beta$-dystrobrevin in both mossy fiber and climbing fiber synapses. It is unclear whether dysbindin in the cerebellum is presynaptic or postsynaptic. In fact, as is the case for other putative members of the DPC, dysbindin appears to be presynaptic (or transsynaptic) in some locations; for example mossy fiber glomeruli terminals in the granular layer (as reported for dystrophin in the retina, in which it is associated with the presynaptic membrane of the 
outer plexiform layer; Ueda et al., 1995), and postsynaptic at others (for example, in climbing fiber synapses on Purkinje cell primary dendrites, as reported for dystrophin at the neuromuscular junction) (for review, see Blake et al., 2002).

Abnormal anti-dysbindin immunostaining in $m d x$ may reflect either mossy fiber sprouting, ectopic dysbindin expression by other mossy fibers, or the unmasking of normally concealed epitopes. Mossy fiber compartmentation is established early in development through the direct interaction between afferent growth cones and embryonic Purkinje cell clusters (for review, see Sotelo and Wassef, 1991), and it is refractory to manipulation in the adult. For example, when the spinocerebellar tracts were lesioned, the afferent topography of the neighboring cuneocerebellar projections was unaffected, suggesting that sprouting and/or competitive interactions for neighboring target space do not play a significant role in the maintenance of normal topography (Ji and Hawkes, 1995). Abnormal topography is seen in some mouse mutants in which Purkinje cells are affected (Sotelo and Wassef, 1991), but there is no evidence that the topography of the target tissue in $m d x$ is abnormal (zebrin II, nNOS, and calretinin are all distributed normally).

In muscle, the absence of dystrophin in $m d x$ tissue results in the upregulation of dysbindin expression (Benson et al., 2001). The situation may be similar in the cerebellum. Counts of glomeruli immunoreactive for dysbindin in the granular layer of $m d x$ mice reveal many additional dysbindin-immunoreactive terminals. Therefore, dysbindin immunoreactivity in mossy fiber glomeruli that are normally unreactive seems a more plausible explanation. It is unclear why no upregulation was detected by Western blotting. Perhaps the robust increases seen by immunocytochemistry in the NZ are too small a fraction of the total dysbindin, taking into account other cerebellar regions plus the Purkinje cell-associated antigen, which are unchanged in $m d x$. Alternatively, more dysbindin-immunoreactive mossy fiber terminals may be stained because epitopes on the dysbindin protein that are normally masked in the DPC are unmasked in $m d x$ because of the lack of dystrophin; this would also be consistent with the absence of changes in other mossy fiber synaptic proteins (Fig. 8). Whatever the explanation (sprouting, ectopic expression or structural abnormalities in a particular family of DPCs) the finding of abnormalities in the posterior cerebellar vermis in $m d x$ may help to explain some of the neurological deficits in muscular dystrophy and schizophrenia. Approximately one-third of children diagnosed with Duchenne muscular dystrophy show signs of dyslexia and mild mental retardation (for review, see Blake and Kroger, 2000). First, deficits in verbal working memory, a substantial component of the cognitive impairment in Duchenne muscular dystrophy (Hinton et al., 2000), are believed to have cerebellar involvement (Desmond et al., 1997). Second, it is becoming well accepted that the reading deficits in dyslexia are accompanied by general impairments in the ability to perform automatic motor tasks that are thought to depend on the cerebellum. Third, the mossy fiber projections to the NZ, the region abnormal in $m d x$, is associated with the regulation of eye movements (for review, see Lewis and Zee, 1993; Raymond et al., 1996; Raymond, 1998); saccadic eye movements are selectively impaired in muscular dystrophy (for review, see Lui et al., 2001; Anderson et al., 2002). The same is true in schizophrenia (Avila et al., 2002a,b). Given recent evidence of linkages between singlenucleotide polymorphisms in the 6 p22.3 region of the human ortholog of mouse dysbindin and inherited schizophrenia (Straub et al., 2002) and of structural abnormalities in the cerebellar vermis of schizophrenia patients (Ichimiya et al., 2001;
Okugawa et al., 2002), we speculate that abnormalities in cerebellar afferent pathways may contribute to the cognitive and eye movement control deficits in patients with muscular dystrophy and schizophrenia.

\section{References}

Ahn AH, Dziennis S, Hawkes R, Herrup K (1994) The cloning of zebrin II reveals its identity with aldolase C. Development 120:2081-2090.

Akintunde A, Eisenman LM (1994) External cuneocerebellar projections and Purkinje cell zebrin II bands: a direct comparison of parasagittal banding in the mouse cerebellum. J Chem Neuroanat 7:75-86.

Anderson JL, Head SI, Rae C, Morley JW (2002) Brain function in Duchenne muscular dystrophy. Brain 125:4-13.

Armstrong CL, Hawkes R (2000) Pattern formation in the cerebellar cortex. Biochem Cell Biol 78:551-562.

Armstrong CL, Krueger AM, Currie RW, Hawkes R (2000) Constitutive expression of the $25 \mathrm{kDa}$ heat shock protein $\mathrm{Hsp} 25$ reveals novel parasagittal bands of Purkinje cells in the adult mouse cerebellar cortex. J Comp Neurol 416:383-397.

Armstrong CL, Krueger-Naug AMR, Currie RW, Hawkes R (2001) Expression of heat-shock protein Hsp25 in mouse Purkinje cells during development reveals novel features of cerebellar compartmentation. J Comp Neurol 429:7-21.

Avila MT, Hong E, Thaker GK (2002a) Current progress in schizophrenia research: eye movement abnormalities in schizophrenia: what is the nature of the deficit? J Nerv Ment Dis 190:479-480.

Avila MT, Weiler MA, Lahti AC, Tamminga CA, Thaker GK (2002b) Effects of ketamine on leading saccades during smooth-pursuit eye movements may implicate cerebellar dysfunction in schizophrenia. Am J Psychiatry 159:1490-1496.

Barmack NH, Baughman RW, Eckenstein FP (1992a) Cholinergic innervation of the cerebellum of the rat by secondary vestibular afferents. Ann NY Acad Sci 656:566-579.

Barmack NH, Baughman RW, Eckenstein FP (1992b) Cholinergic innervation of the cerebellum of rat, rabbit, cat, and monkey as revealed by choline acetyltransferase activity and immunohistochemistry. J Comp Neurol 317:233-249.

Barmack NH, Baughman RW, Eckenstein FP, Shojaku H (1992c) Secondary vestibular cholinergic projection to the cerebellum of rabbit and rat as revealed by choline acetyltransferase immunohistochemistry, retrograde and orthograde tracers. J Comp Neurol 317:250-270.

Benson MA, Newey SE, Martin-Rendon E, Hawkes R, Blake DJ (2001) Dysbindin, a novel coiled-coil-containing protein that interacts with the dystrobrevins in muscle and brain. J Biol Chem 276:24232-24241.

Blake DJ, Kroger S (2000) The neurobiology of Duchenne muscular dystrophy: learning lessons from muscle? Trends Neurosci 23:92-99.

Blake DJ, Nawrotzki R, Loh NY, Gorecki DC, Davies KE (1998) betadystrobrevin, a member of the dystrophin-related protein family. Proc Natl Acad Sci USA 95:241-246.

Blake DJ, Hawkes R, Benson MA, Beesley PW (1999) Different dystrophinlike complexes are expressed in neurons and glia. J Cell Biol 147:645-658.

Blake DJ, Weir A, Newey SE, Davies KE (2002) Function and genetics of dystrophin and dystrophin-related proteins in muscle. Physiol Rev 82:291-329.

Boegman RJ, Parent A, Hawkes R (1988) Zonation in the rat cerebellar cortex: patches of high acetylcholinesterase activity in the granular layer are congruent with Purkinje cell compartments. Brain Res 448:237-251.

Braun JE, Scheller RH (1995) Cysteine string protein, a DnaJ family member, is present on diverse secretory vesicles. Neuropharmacology 34:1361-1369.

Brenman JE, Chao DS, Xia H, Aldape K, Bredt DS (1995) Nitric oxide synthase complexed with dystrophin and absent from skeletal muscle sarcolemma in Duchenne muscular dystrophy. Cell 82:743-752.

Brochu G, Maler L, Hawkes R (1990) Zebrin II: A polypeptide antigen expressed selectively by Purkinje cells reveals compartments in rat and fish cerebellum. J Comp Neurol 291:538-552.

Desclin JC (1976) Early terminal degeneration of cerebellar climbing fibers after destruction of the inferior olive in the rat. Synaptic relationships in the molecular layer. Anat Embryol (Berl) 149:87-112.

Desclin JC, Colin F (1980) The olivocerebellar system. II. Some ultrastructural correlates of inferior olive destruction in the rat. Brain Res 187:29-46.

Desmond JE, Gabrieli JD, Wagner AD, Ginier BL, Glover GH (1997) Lob- 
ular patterns of cerebellar activation in verbal working-memory and fingertapping tasks as revealed by functional MRI. J Neurosci 17:9675-9685.

Dino MR, Willard FH, Mugnaini E (1999) Distribution of unipolar brush cells and other calretinin immunoreactive components in the mammalian cerebellar cortex. J Neurocytol 28:99-123.

Dino MR, Nunzi MG, Anelli R, Mugnaini E (2000) Unipolar brush cells of the vestibulocerebellum: afferents and targets. Prog Brain Res 124:123-137.

Eisenman LM, Hawkes R (1993) Antigenic compartmentation in the mouse cerebellar cortex: zebrin and HNK-1 reveal a complex, overlapping molecular topography. J Comp Neurol 335:586-605.

Fykse EM, Takei K, Walch-Solimena C, Geppert M, Jahn R, De Camilli P, Sudhof TC (1993) Relative properties and localizations of synaptic vesicle protein isoforms: the case of the synaptophysins. J Neurosci 13:4997-5007.

Gravel C, Hawkes R (1990) Parasagittal organization of the rat cerebellar cortex: direct comparison of Purkinje cell compartments and the organization of the spinocerebellar projection. J Comp Neurol 291:79-102.

Hawkes R (1997) An anatomical model of cerebellar modules. Prog Brain Res 114:39-52.

Hawkes R, Eisenman L (1997) Stripes and zones: the origins of regionalization of the adult cerebellum. Perspect Dev Neurobiol 5:95-105.

Hawkes R, Turner RW (1994) Compartmentation of NADPH-diaphorase activity in the mouse cerebellar cortex. J Comp Neurol 346:499-516.

Herrup K, Kuemerle B (1997) The compartmentalization of the cerebellum. Annu Rev Neurosci 20:61-90.

Hess DT, Voogd J (1986) Chemoarchitectonic zonation of the monkey cerebellum. Brain Res 369:383-387.

Hinton VJ, De Vivo DC, Nereo NE, Goldstein E, Stern Y (2000) Poor verbal working memory across intellectual level in boys with Duchenne dystrophy. Neurology 54:2127-2132.

Ichimiya T, Okubo Y, Suhara T, Sudo Y (2001) Reduced volume of the cerebellar vermis in neuroleptic-naive schizophrenia. Biol Psychiatry 49:20-27.

Jaarsma D, Dino MR, Cozzari C, Mugnaini E (1996) Cerebellar choline acetyltransferase positive mossy fibres and their granule and unipolar brush cell targets: a model for central cholinergic nicotinic neurotransmission. J Neurocytol 25:829-842.

Jaarsma D, Ruigrok TJ, Caffe R, Cozzari C, Levey AI, Mugnaini E, Voogd J (1997) Cholinergic innervation and receptors in the cerebellum. Prog Brain Res 114:67-96.

Ji Z, Hawkes R (1994) Topography of Purkinje cell compartments and mossy fiber terminal fields in lobules II and III of the rat cerebellar cortex: spinocerebellar and cuneocerebellar projections. Neuroscience 61:935-954.

Ji Z, Hawkes R (1995) Developing mossy fiber terminal fields in the rat cerebellar cortex may segregate because of Purkinje cell compartmentation and not competition. J Comp Neurol 359:197-212.

Knuesel I, Bornhauser BC, Zuellig RA, Heller F, Schaub MC, Fritschy JM (2000) Differential expression of utrophin and dystrophin in CNS neurons: an in situ hybridization and immunohistochemical study. J Comp Neurol 422:594-611.

Kohan SA, Pescatori M, Brecha NC, Mastrogiacomo A, Umbach JA, Gundersen CB (1995) Cysteine string protein immunoreactivity in the nervous system and adrenal gland of rat. J Neurosci 15:6230-6238.

Leclerc N, Beesley PW, Brown I, Colonnier M, Gurd JW, Paladino T, Hawkes R (1989) Synaptophysin expression during synaptogenesis in the rat cerebellar cortex. J Comp Neurol 280:197-212.

Leclerc N, Doré L, Parent A, Hawkes R (1990) The compartmentalization of the monkey and rat cerebellar cortex: zebrin I and cytochrome oxidase. Brain Res 506:70-78.

Lewis RF, Zee DS (1993) Ocular motor disorders associated with cerebellar lesions: pathophysiology and topical localization. Rev Neurol (Paris) 149:665-677.

Lidov HG, Byers TJ, Watkins SC, Kunkel LM (1990) Localization of dystro- phin to postsynaptic regions of central nervous system cortical neurons. Nature 348:725-728.

Lui F, Fonda S, Merlini L, Corazza R (2001) Saccadic eye movements are impaired in Duchenne muscular dystrophy. Doc Ophthalmol 103:219-228.

Marani E, Voogd J (1977) An acetylcholinesterase band pattern in the molecular layer of the cat cerebellum. J Anat 124:335-345.

Mugnaini E, Floris A (1994) The unipolar brush cell: a neglected neuron of the mammalian cerebellar cortex. J Comp Neurol 339:174-180.

Mugnaini E, Dino MR, Jaarsma D (1997) The unipolar brush cells of the mammalian cerebellum and cochlear nucleus: cytology and microcircuitry. Prog Brain Res 114:131-150.

Nunzi MG, Mugnaini E (2000) Unipolar brush cell axons form a large system of intrinsic mossy fibers in the postnatal vestibulocerebellum. J Comp Neurol 422:55-65.

Nunzi MG, Shigemoto R, Mugnaini E (2002) Differential expression of calretinin and metabotropic glutamate receptor mGluR $1 \alpha$ defines subsets of unipolar brush cells in mouse cerebellum. J Comp Neurol 451:189-199.

Oberdick J, Baader SL, Schilling K (1998) From zebra stripes to postal zones: deciphering patterns of gene expression in the cerebellum. Trends Neurosci 21:383-390.

Okugawa G, Sedvall G, Nordstrom M, Andreasen N, Pierson R, Magnotta V, Agartz I (2002) Selective reduction of the posterior superior vermis in men with chronic schizophrenia. Schizophr Res 55:61-67.

Ozol K, Hawkes R (1997) The compartmentation of the granular layer of the cerebellum. Histol Histopathol 12:171-184.

Ozol K, Hayden JM, Oberdick J, Hawkes R (1999) Transverse zones in the vermis of the mouse cerebellum. J Comp Neurol 412:95-111.

Raymond JL (1998) Learning in the oculomotor system: from molecules to behavior. Curr Opin Neurobiol 8: 770-776.

Raymond JL, Lisberger SG, Mauk MD (1996) The cerebellum: a neuronal learning machine? Science 272:1126-1131.

Schilling K, Schmidt HH, Baader SL (1994) Nitric oxide synthase expression reveals compartments of cerebellar granule cells and suggests a role for mossy fibers in their development. Neuroscience 59:893-903.

Schwab SG, Knapp M, Mondabon S, Hallmayer J, Borrmann-Hassenbach M, Albus M, Lerer B, Rietschel M, Trixler M, Maier W, Wildenauer DB (2003) Support for association of schizophrenia with genetic variation in the 6p22.3 gene, dysbindin, in sib-pair families with linkage and in an additional sample of triad families. Am J Hum Genet 72:185-190.

Serapide MF, Cicirata F, Sotelo C, Panto MR, Parenti R (1994) The pontocerebellar projection: longitudinal zonal distribution of fibers from discrete regions of the pontine nuclei to vermal and parafloccular cortices in the rat. Brain Res 644:175-180.

Sotelo C, Wassef M (1991) Cerebellar development: afferent organization and Purkinje cell heterogeneity. Phil Trans R Soc Lond B Biol Sci 331:307-313.

Straub RE, Jiang Y, MacLean CJ, Ma Y, Webb BT, Myakishev MV, HarrisKerr C, Wormley B, Sadek H, Kadambi B, Cesare AJ, Gibberman A, Wang X, O'Neill FA, Walsh D, Kendler KS (2002) Genetic variation in the 6 p22.3 gene DTNBP1, the human ortholog of the mouse dysbindin gene, is associated with schizophrenia. Am J Hum Genet 71:337-348.

Towbin H, Staehelin T, Gordon J (1979) Electrophoretic transfer of proteins from polyacrylamide gels to nitrocellulose sheets: procedure and some applications. Proc Natl Acad Sci USA 76:4350-4354.

Ueda H, Kobayashi T, Mitsui K, Tsurugi K, Tsukahara S, Ohno S (1995) Dystrophin localization at presynapse in rat retina revealed by immunoelectron microscopy. Invest Ophthalmol Vis Sci 36:2318-2322.

Wiedenmann B, Franke WW (1985) Identification and localization of synaptophysin, an integral membrane glycoprotein of $\mathrm{Mr}$ 38,000 characteristic of presynaptic vesicles. Cell 41:1017-1028.

Yan XX, Yen LS, Garey LJ (1993) Parasagittal patches in the granular layer of the developing and adult rat cerebellum as demonstrated by NADPHdiaphorase histochemistry. NeuroReport 4:1227-1230. 